\title{
Berichtigung.
}

In der Arbeit:

\section{Pepsinbestimmung im Mageninhalt mit Hilfe DES PULFRICH-PHOTOMETERS NACH ZEISS}

\author{
von \\ SIEGFRIED PETERSEN \\ (MIKROCHEMIE XII, 21ว [1932])
}

soll es heißen:

Seite 217, Zeile 14 v. $0 .: 0,1 \%$ (statt: $0,01 \%$ ).

Seite 219, Zeile 9 v. o.: unzersetzt (statt: umgesetzt).

Seite 220, Zeile 21 v. 0.: 0,015:1 (statt: 0,015\%).

Seite 220, Zeile 23 v. o.: Pepsinkonzentration im verdünnten

Magensaft, ausgedrückt in Prozent Witte-Pepsin (statt:

Magensaftverdünnung).

Seite 220, erste Spalte der Tabelle 2: Da die Tabelle die Pepsinwerte, gemessen in Prozent Witte-Pepsin, in den Magensaftverdünnungen enthält, gibt Spalte 1 nicht Prozente an, sondern die Anzahl Kubikzentimeter Mageninhalt in $1 \mathrm{ccm}$ der angewandten verdünnten Lösung.

Seite 221, Zeile 9 v. o.: Pepsingehalt (statt: Pesingehalt). 